\title{
Mesothelioma and Colorectal Cancer: Report of Four Cases with Synchronous and Metachronous Presentation
}

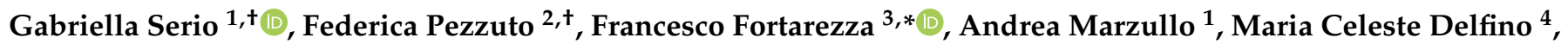 \\ Antonio d'Amati ${ }^{1}{ }^{1}$, Daniele Egidio Romano ${ }^{1}$, Sonia Maniglio ${ }^{1} \mathbb{D}$, Concetta Caporusso ${ }^{1}$, Teresa Lettini ${ }^{1}{ }^{1}$, \\ Domenica Cavone ${ }^{4}$ (i) and Luigi Vimercati ${ }^{4}$ (B)
}

Citation: Serio, G.; Pezzuto, F.; Fortarezza, F.; Marzullo, A.; Delfino, M.C.; d'Amati, A.; Romano, D.E.; Maniglio, S.; Caporusso, C.; Lettini, T.; et al. Mesothelioma and Colorectal Cancer: Report of Four Cases with Synchronous and Metachronous Presentation. Int. J. Mol. Sci. 2022, 23, 2630. https://doi.org/10.3390/ ijms 23052630

Academic Editors: Akira Hara and Hiroyuki Tomita

Received: 25 January 2022

Accepted: 25 February 2022

Published: 27 February 2022

Publisher's Note: MDPI stays neutral with regard to jurisdictional claims in published maps and institutional affiliations.

Copyright: (C) 2022 by the authors. Licensee MDPI, Basel, Switzerland. This article is an open access article distributed under the terms and conditions of the Creative Commons Attribution (CC BY) license (https:// creativecommons.org/licenses/by/ $4.0 /)$
1 Department of Emergency and Organ Transplantation-DETO, Pathology Unit, University of Bari, G. Cesare 1 Sq., 70121 Bari, Italy; gabriella.serio1@uniba.it (G.S.); andrea.marzullo@uniba.it (A.M.); damatiantonio@yahoo.it (A.d.); danieleromano95@gmail.com (D.E.R.); sonya1996@hotmail.it (S.M.); kcaporusso.c@libero.it (C.C.); lettinit@yahoo.com (T.L.)

2 Department of Cardiac, Thoracic, Vascular Sciences and Public Health-DCTV, Pathology Unit, University of Padova, 61 N. A. Gabelli St., 35121 Padova, Italy; federica.pezzuto@unipd.it

3 Pathology Unit, University Hospital of Padova, University of Padova, 61 N. A. Gabelli St., 35121 Padova, Italy

4 Department of Interdisciplinary Medicine, Occupational Health Division, Internal Medicine Unit, University of Bari, G. Cesare 1 Sq., 70121 Bari, Italy; maria.delfino@uniba.it (M.C.D.);

domenica.cavone@uniba.it (D.C.); luigi.vimercati@uniba.it (L.V.)

* Correspondence: francesco.fortarezza@aopd.veneto.it

+ These authors contributed equally to this work.

\begin{abstract}
There is evidence that asbestos could play a role in the carcinogenesis of digestive cancers The presence of asbestos fibres in histological samples from gastric, biliary, colon cancers has been reported, but the mechanism is still controversial. It has been hypothesised that asbestos reaches these sites, especially through contaminated water; however, some experimental studies have shown that the inhaled fibres are mobile, so they can migrate to many organs, directly or via blood and lymph flow. We report four unusual cases of colorectal cancers in patients with a long history of asbestos exposure who also developed synchronous or metachronous mesothelioma. We evaluated the roles of BRCA associated protein-1 (BAP1) and cyclin-dependent kinase inhibitor 2A (CDKN2A) in colon cancer and mesothelioma to support the hypothesis that $B A P-1$ and $C D K N 2 A$ are tumour suppressor genes involved in disease progression, recurrence, or death in both digestive cancers and mesothelioma. Potentially, these markers may be used as predictors of worse prognosis, but we also stress the importance of clinical surveillance of exposed patients because asbestos could induce cancer in any organ.
\end{abstract}

Keywords: asbestos; mesothelioma; peritoneum; pleura; colon cancer; BAP1; CDKN2A

\section{Introduction}

The carcinogenicity of asbestos is known, and the relationships between asbestos and numerous human cancers (laryngeal, ovarian, testis, prostate, and bladder cancers) have been reported [1-8]. Furthermore, much evidence supports the association between asbestos exposure alone or in synergy with other risk factors (i.e., radiation or smoking) and colon cancer [9-12].

However, aspects concerning the mode of absorption (respiratory inhalation or oral ingestion of contaminated water), the time of exposure, the type of exposure (occupational or environmental), the concentration, and the relationship between the different asbestos fibres and cancers of other sites have not been clarified [13]. The known mechanisms of asbestos carcinogenesis are chronic inflammation (including frustrated phagocytosis) and loss of tumour-suppressive mechanisms. Although several genetic alterations have been reported, the most frequent chromosomal aberrations in pleural and peritoneal mesotheliomas are loss at 3p21 (BRCA1 associated protein-1—BAP1) and 9p21 (cyclin-dependent 
kinase inhibitor $2 \mathrm{~A}-\mathrm{CDKN} 2 \mathrm{~A}) . \mathrm{CDKN} 2 \mathrm{~A}$ is a tumour suppressor gene that prevents uncontrolled cell proliferation by initiating cell cycle arrest and apoptosis. Homozygous CDKN2A deletion is more frequent in pleural mesothelioma, represents a good diagnostic marker and seems to be related to a poor prognosis. BAP1 is a nuclear-localised deubiquitinating enzyme involved in many processes, including DNA damage response and regulation of the cell cycle and cell proliferation [7,14-18].

Colon cancer represent the third most frequent malignant disease in terms of incidence and mortality worldwide [19]. Some epidemiological observations suggest an increased risk of colorectal cancer in asbestos-exposed patients $[9,10,14,19,20]$, even if the molecular mechanisms have not yet been investigated and clarified. Moreover, according to the recent consensus statement on asbestos-related neoplasms, colorectal cancers cannot yet be considered as asbestos-related diseases [21,22].

The aim of the present study was to report four cases of colon cancer arising in asbestos-exposed patients, two of whom were affected by synchronous mesothelioma and two of whom developed mesotheliomas (metachronous) four years later with the analysis of the molecular status of $C D K N 2 A$ and BAP1 expression in all tumours.

\section{Results}

Clinicopathological data, survival, asbestos exposure time, family history of cancer, BAP1 immunohistochemistry, and CDKN2A FISH results are shown in Tables 1 and 2. The main histological, immunohistochemical, and molecular images of each patient are grouped in Figure 1. No asbestos fibres were detected in any of the colorectal adenocarcinoma samples. However, asbestos bodies were identified in in the ascitic fluid cellblock of the patients 1 (Figure 2).

Table 1. Clinical data of patients with colorectal cancer and mesothelioma.

\begin{tabular}{|c|c|c|c|c|c|}
\hline Patient & $\operatorname{Sex}(M / F)$ & Age (Years) & Asbestos Exposure & Overall Survival (Months) & Family Cancer History \\
\hline 1 & $\mathrm{M}$ & 70 & $\begin{array}{l}\text { 1958-1989 (occupational, } \\
\text { merchant marine deck officer) }\end{array}$ & 51 & $\begin{array}{l}\text { Father lung cancer } \\
\text { Sibling lung cancer } \\
\text { Sibling hepatocarcinoma } \\
\text { Sibling colon cancer }\end{array}$ \\
\hline 2 & $\mathrm{~F}$ & 58 & $\begin{array}{l}\text { 1971-1975 and 1980-1990 } \\
\text { (occupational, dressmaker) }\end{array}$ & 74 (alive) & Father laryngeal cancer \\
\hline 3 & M & 71 & $\begin{array}{l}\text { 1960-1980 (occupational, carpenter) } \\
\text { 1957-1975 (occupational, welder) }\end{array}$ & 42 & $\begin{array}{c}\text { None } \\
\text { Father colon cancer }\end{array}$ \\
\hline 4 & M & 89 & $\begin{array}{l}\text { 1971-2018 (environmental, resident near } \\
\text { asbestos factory) }\end{array}$ & 5 & $\begin{array}{c}\text { Sibling bone tumour } \\
\text { Sibling pancreatic carcinoma }\end{array}$ \\
\hline
\end{tabular}

Table 2. Pathological and molecular data of patients with synchronous and metachronous mesothelioma.

\begin{tabular}{|c|c|c|c|c|c|c|c|}
\hline Patient & Tumour & Site & pTNM & BAP1 (IHC) & $\begin{array}{c}\text { CDKN2A Homozygous } \\
\text { Deletion }\end{array}$ & $\begin{array}{c}\text { CDKN2A Heterozygous } \\
\text { Deletion }\end{array}$ & Therapy \\
\hline $1 *$ & $\begin{array}{c}\text { High grade } \\
\text { adenocarcinoma, NOS }\end{array}$ & Colon & T2N0M0 & Score $0(0 \%)$ & $32 \%$ & $50 \%$ & FOLFOX \\
\hline $2 * *$ & $\begin{array}{l}\text { Low grade } \\
\text { adenocarcinoma, NOS }\end{array}$ & Rectum & T2N1cM0 & Score $4(90 \%)$ & $28 \%$ & $62 \%$ & FOLFOX \\
\hline $3 * *$ & $\begin{array}{c}\text { Low grade } \\
\text { adenocarcinoma, NOS }\end{array}$ & Rectum & T3N2aM0 & Score $4(78 \%)$ & $23 \%$ & $64 \%$ & FOLFOX \\
\hline $4 *$ & $\begin{array}{l}\text { Low grade } \\
\text { adenocarcinoma, NOS }\end{array}$ & Rectum & T3N0M0 & Score $0(10 \%)$ & $30 \%$ & $73 \%$ & - \\
\hline $1 *$ & $\begin{array}{l}\text { Epithelioid } \\
\text { mesothelioma }\end{array}$ & Pleura & - & Score $0(0 \%)$ & $70 \%$ & $12 \%$ & Palliative \\
\hline $2 * *$ & $\begin{array}{l}\text { Epithelioid } \\
\text { mesothelioma }\end{array}$ & Pleura & - & Score $3(60 \%)$ & $44 \%$ & $54 \%$ & Palliative \\
\hline $3 * *$ & $\begin{array}{l}\text { Biphasic (Epithelioid } \\
\text { adenomatoid/solid } \\
80 \% \text { ) mesothelioma }\end{array}$ & Peritoneum & - & Score $3(55 \%)$ & $90 \%$ & $10 \%$ & Palliative \\
\hline $4^{*}$ & $\begin{array}{l}\text { Biphasic (Epithelioid } \\
\text { solid/trabecular 70\%) } \\
\text { mesothelioma }\end{array}$ & Peritoneum & - & Score $0(0 \%)$ & $75 \%$ & $20 \%$ & Palliative \\
\hline
\end{tabular}






Figure 1. Each box groups the main histological, immunohistochemical, and molecular images of both colon cancer and mesothelioma of each patient as follows: histological microphotographs of colon adenocarcinomas (a), haematoxylin and eosin stain (original magnification $\times 100$ ) and mesotheliomas (b), haematoxylin and eosin stain, original magnification $\times 100$ (cases 1, 2, and 3), $\times 200$ (Case 4); immunohistochemistry for BAP1 in colon adenocarcinomas (c), original magnification $\times 100$ (case 1 and 4), $\times 200$ (cases 2 and 3); FISH analysis for CDKN2A (p16) in colon cancer samples (d); immunohistochemistry for BAP1 in mesotheliomas (e), original magnification $\times 100$ (cases 1, 3, and 4 ), $\times 200$ (case 2). The pathological, immunohistochemical, and molecular findings are described in Table 2.

The complete absence of BAP1 expression was found in two patients, both in intestinal tumours and in mesotheliomas.

All tumours had CDKN2A deletions above the cut-off, heterozygous or homozygous. In particular, intestinal tumours showed higher values of heterozygous deletions than homozygous ones (median value $63 \%$ vs. $29 \%$, respectively) while mesotheliomas showed a completely opposite scenario with higher percentages of homozygous deletions (median value $16 \%$ vs. $72.5 \%)$.

In situ and molecular biomarker testing for colorectal cancer did not detect any mutations. Three patients $(1,2,3)$ received adjuvant chemotherapy (FOLFOX, 5-FU/ $\mathrm{LV}+$ oxaliplatin) for colon cancer; one patient (case 4) received only palliative chemotherapy due to poor performance status. Patients with metachronous mesothelioma received 
palliative chemotherapy (cisplatin + pemetrexed or gemcitabine), and patient 1 received treatment with cisplatin after FOLFOX chemotherapy.

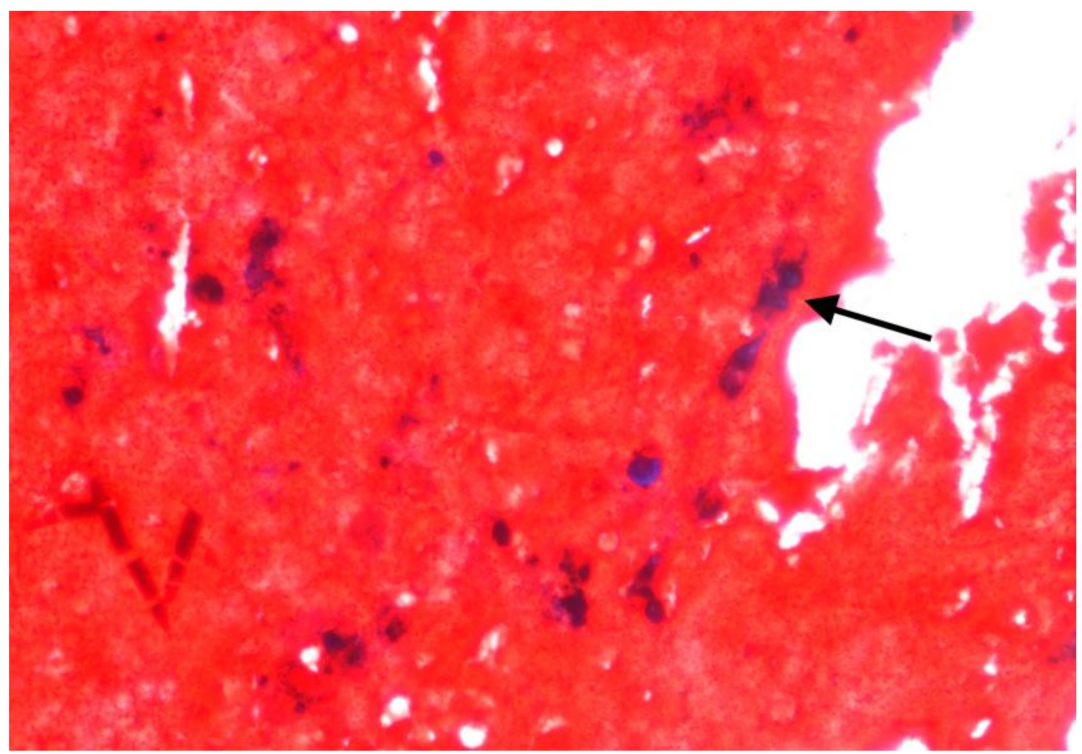

Figure 2. Cytoblock of the ascitic fluid of patient 1. An asbestos body is clearly visible (arrow) (Perls' Prussian Blue stain, original magnification $\times 400$ ).

\section{Discussion}

Our study is the first in the literature to analyse the expression of BAP1 and the deletion of $C D K N 2 A$ in four colon adenocarcinomas with synchronous or metachronous mesothelioma of patients with well documented occupational and environmental exposure. Molecular analysis for CDKN2A documented the deletion of the gene in all eight tumours, with a prevalence of heterozygous deletion in the colorectal cancers and homozygous one in mesotheliomas. Moreover, in two cases both mesothelioma and intestinal carcinoma showed loss of BAP1 expression.

An increased risk of asbestos-related tumours appears evident owing to respiratory exposure, but the risk of cancer development after oral ingestion of asbestos from drinking asbestos-contaminated water remains unclear. Although inhaled asbestos has undoubtedly greater toxicity in the lung and therefore in the pleura, it has been shown that, through blood or lymphatic flow, fibres can translocate to other organs [23]. In support of the first observations reported by Selikof et al. [24], experimental studies have demonstrated the passage of chrysotile and crocidolite fibres across the gastrointestinal wall, suggesting the hypothesis of fibre dissemination, inhaled or ingested, through the blood and/or lymphatic flow [25]. Auerbach et al. [26], in a series of 19 autopsy cases, observed the presence of asbestos fibres or ferruginous bodies not only in the lung but also in other organs. In our case series, we histologically identified an asbestos body in the ascitic fluid of a patient with pleural mesothelioma and colon adenocarcinoma even if microanalysis studies would be desirable to better deepen the research. The effects of oral ingestion of asbestos-contaminated water are discordant between studies; in fact, whereas many studies did not reveal an excess of cancer mortality after oral asbestos ingestion, other studies report a clear dose-response relationship between different asbestos fibres and digestive cancers [27,28]. Clin et al. [29] and Paris et al. [10] observed a significant increase in death in patients who had developed oesophageal or colon cancers and who had a documented history of asbestos exposure. The presence of asbestos fibres in the colon or other viscera cannot be considered accidental but is related to the development of the disease. Therefore, the association between colon cancer that represents the third most frequent malignant disease in terms of incidence and mortality worldwide in workers or in subjects otherwise exposed to asbestos appears consistent. Similarly to our cases, there is some evidence that 
in workers, the inhalation of asbestos increases the risk of colorectal cancer [30] but these often-stringent epidemiological observations are limited and/or not consistent due to the absence of molecular markers supporting the development and progression of cancer into sites other than the mesothelium. The collection of these cases to reach an adequate number of evidence to support statistical correlations would be desirable.

From a molecular point of view, many colorectal cancers show chromosomal instability, characterised by gains or losses of numerous chromosomal regions that drive the process from neoplastic growth to invasiveness and metastasis development [19]. Some studies reported an increased risk of colorectal cancer in patients with loss of heterozygosity at the $B R C A 1$ gene locus, which shows shorter disease-free survival [31,32]. Mutations of BAP1 have been described in multiple human cancers, and their role often depends on the site of the tumour and the triggering factors. Regarding our case-series, BAP1 was not expressed in two cases and, interestingly, in both mesotheliomas and intestinal adenocarcinomas. This feature raises the suspicion of the presence of a BAP1 germline mutation, also because the family history of these two patients showed many more cases of neoplasia than the other two. This would have been an important aspect to investigate in our case studies but unfortunately it was not possible to evaluate the possible germline mutation of $B A P 1$ in the described cases for the lack of consent to genetic analyses. Germline and somatic BAP1 inactivation predispose patients to a higher risk of both familial and sporadic mesothelioma. Patients with germline $B A P 1$ mutations seem to have better survival than those with somatic alterations [33]. The role of $B A P 1$ in colorectal cancer is unclear and poorly investigated. Tang et al. [34] observed that BAP1 is downregulated in colon cancer and associated with shorter survival. It would be of interest to study this marker in this direction to assess its prognostic role in tumours other than mesothelioma.

Another interesting finding in our study was that $C D K N 2 A$ deletion was present in all cases, in particular homozygous deletions in mesotheliomas and heterozygous deletions in intestinal neoplasms. Deletion of $C D K N 2 A$ is frequent in mesothelioma and its prognostic implications have been described [35,36]. Losses or inactivation of $C D K N 2 A$ have also been observed in colon cancer and seem to be related to tumour progression and prognosis. Berg et al. [37], analysing a series of colon cancers, observed that higher copy number alterations and losses at 9p21 were significantly related to advanced stage and shorter survival. Although the number of cases is limited and the comparison of survivals is inapplicable, our case series enriches this evidence. Moreover, the combination with the lack of BAP1 expression and the onset of mesothelioma in the same patients may lead us to speculate on a possible common pathway of carcinogenesis linked to asbestos.

The intrinsic limitations of our study, such as the retrospectivity of the study design and the limited number of cases, make this result ambitious and future study necessary. Nevertheless, the rarity of mesothelioma itself and its co-occurrence with other neoplasms give value to the report. The molecular investigations we have performed were limited to specific targets. Other genes could be involved by biallelic inactivation, such as NF2 [38], typically lost for monosomy or large deletion of chromosome 22. This aspect brings out another necessity, namely the employment of more sophisticated sequencing techniques, capable to detect other mutations and small fragment deletion. Lastly, to strengthen the link between asbestos and colorectal tumours, the search for asbestos fibres in intestinal cancer samples should be performed with electron microscopy coupled with microanalysis. This, together with the collection of more cases that will be analysed based on next-generation or other high-throughput sequencing methodologies, will represent the goal of future communications.

\section{Materials and Methods}

The present study was conducted in accordance with local ethics regulations and the Helsinki Declaration. The medical history and clinicopathological information of each patient were obtained from treatment records. Patients' asbestos exposure (occupational and/or environmental), clinical data (sex, age, and stage of the disease), date of diagnosis, 
and survival were collected through Apulia regional mesothelioma register questionnaires, classified according to the National Mesothelioma Register (ReNaM) criteria (https: / / www. inail.it/cs/internet/docs/renamlineeguida2005-pdf.pdf; accessed on 24 February 2022), and encoded in an electronic database.

Colon cancer symptoms were the first clinical manifestation; all patients underwent surgery, and none of them received chemotherapy and/or radiotherapy prior to the surgery. After radical resection, all pathological tissue specimens were formalin-fixed and paraffinembedded. Haematoxylin-eosin-stained sections were reviewed by two expert pathologists to confirm the diagnosis of colon and mesothelioma synchronous tumours (two cases). For colon cancer diagnosis, the WHO [19] criteria were applied, and for mesothelioma, a wide panel of immunohistochemical antibodies was used, following WHO recommendations [7]. In situ and molecular biomarker testing for colorectal cancer (including mismatch repair protein expression and characterisation of RAS mutations) was also performed. Asbestos fibres were searched in histological specimens of colorectal carcinomas and in an available case of cytoblock of ascitic fluid (Patient 1) using Perls' Prussian Blue stain. The mesothelioma samples were collected from thoracoscopic pleurectomies and omental and peritoneal biopsies.

Colon cancer and mesothelioma were also immunostained for a BAP1 (clone C4, Santa Cruz Biotechnology Inc., dilution 1:400) antibody. BAP1 nuclear expression was scored as negative $(0-10 \%)$, low $(11-25 \%)$, moderate $(26-50 \%)$, or strong $(>50 \%)$ in colon cancer and mesothelioma, as suggested by Tang et al. [32], independent of nuclear intensity.

The status of the CDKN2A gene was determined by fluorescence in situ hybridisation (FISH). A FISH locus specific CDKN2A (9p21) probe (Abbott, Abbott Park, IL, USA) was used to detect chromosome 9 deletion. Vysis LSI CDKN2A/CEP 9 probes are provided in one vial as a mixture of the LSI CDKN2A (p16) probe labelled with Spectrum Orange and the CEP 9 probe labelled with Spectrum Green. The LSI CDKN2A probe spans approximately $222 \mathrm{~kb}$ and contains several genetic loci, including D9S1749, DS1747, p16 (INK4B), p14 (ARF), D9S1748, p15 (INK4B), and D9S1752. The CEP 9 Spectrum Green probe hybridizes to alpha satellite sequences specific to chromosome 9, CE Marked. At least 100 cells were scored for each case. A cut-off of $20 \%$ was used for homozygous deletion. Heterozygous deletion was defined as when $>20 \%$ of the cells showed only one signal or a lower signal number than CEP9.

\section{Conclusions}

Occupational/environmental asbestos exposure deserves continued attention because this mineral defined as a "hidden killer" can reach any organ, and the long latency that characterizes the onset of the tumour could obscure the causal relationship. In tumours arising in asbestos-exposed patients, a further molecular analysis is warranted to evaluate the causality between asbestos exposure and carcinogenesis as an alternative to the most common altered pathways.

Author Contributions: Conceptualisation, D.C., L.V., F.F., F.P. and G.S.; methodology, G.S., F.F. and F.P.; validation, L.V., G.S. and A.M.; formal analysis, A.M., D.C., M.C.D., A.d., D.E.R., S.M., T.L., C.C.; data curation, D.C.; writing-original draft preparation, D.C., G.S. and F.P.; writing-review and editing, D.C., L.V., G.S., F.F. and F.P.; supervision, L.V. All authors have read and agreed to the published version of the manuscript.

Funding: This research received no external funding.

Institutional Review Board Statement: The study was conducted in accordance with the Declaration of Helsinki and national and institutional standards. The study was approved by the local Ethics Committee of the Policlinico-Hospital, Bari, Italy (accession number 5062, 22 June 2016). Written informed consent to the use of tissue for additional studies and for research purpose was obtained from the patients.

Informed Consent Statement: Informed consent was obtained from all subjects involved in the study. 
Data Availability Statement: Data sharing is not applicable to this article.

Conflicts of Interest: The authors declare no conflict of interest.

\section{References}

1. Vimercati, L.; Cavone, D.; Delfino, M.; Bruni, B.; De Maria, L.; Caputi, A.; Sponselli, S.; Rossi, R.; Resta, L.; Fortarezza, F.; et al. Primary Ovarian Mesothelioma: A Case Series with Electron Microscopy Examination and Review of the Literature. Cancers 2021, 13, 2278. [CrossRef]

2. Vimercati, L.; Cavone, D.; Delfino, M.C.; De Maria, L.; Caputi, A.; Ferri, G.M.; Serio, G. Asbestos exposure and malignant mesothelioma of the tunica vaginalis testis: A systematic review and the experience of the Apulia (southern Italy) mesothelioma register. Environ. Health 2019, 18, 1-24. [CrossRef]

3. Serio, G.; Pagliarulo, V.; Marzullo, A.; Punzi, A.; Pezzuto, F.; Gentile, M.; Pennella, A.; Nazzaro, P.; Buonadonna, A.L.; Covelli, C.; et al. Molecular changes of malignant mesothelioma in the testis and their impact on prognosis: Analyses of two cases. Int. J. Clin. Exp. Pathol. 2016, 9, 7658-7667.

4. Dutheil, F. Prostate Cancer and Asbestos: A Systematic Review and Meta-Analysis. Perm. J. 2020, 24. [CrossRef]

5. Hillerdal, G.; Lindholm, C.-E. Laryngeal cancer and asbestos. ORL J. Otorhinolaryngol. Relat. Spec. 1980, 42, 233-241. [CrossRef]

6. Kang, D.-M.; Kim, J.-E.; Kim, Y.-K.; Lee, H.-H.; Kim, S.-Y. Occupational Burden of Asbestos-Related Diseases in Korea, 1998-2013: Asbestosis, Mesothelioma, Lung Cancer, Laryngeal Cancer, and Ovarian Cancer. J. Korean Med. Sci. 2018, 33, e226. [CrossRef] [PubMed]

7. WHO. Thoracic Tumour. In WHO Classification of Tumours, 5th ed.; WHO: Lyon, France, 2021.

8. Offermans, N.S.; Vermeulen, R.; Burdorf, A.; Goldbohm, R.A.; Kauppinen, T.; Kromhout, H.; Brandt, P.A.V.D. Occupational Asbestos Exposure and Risk of Pleural Mesothelioma, Lung Cancer, and Laryngeal Cancer in the Prospective Netherlands Cohort Study. J. Occup. Environ. Med. 2014, 56, 6-19. [CrossRef] [PubMed]

9. Kwak, K.; Paek, D.; Zoh, K.E. Exposure to asbestos and the risk of colorectal cancer mortality: A systematic review and meta-analysis. Occup. Environ. Med. 2019, 76, 861-871. [CrossRef] [PubMed]

10. Paris, C.; Thaon, I.; Hérin, F.; Clin, B.; Lacourt, A.; Luc, A.; Coureau, G.; Brochard, P.; Chamming'S, S.; Gislard, A.; et al. Occupational Asbestos Exposure and Incidence of Colon and Rectal Cancers in French Men: The Asbestos-Related Diseases Cohort (ARDCo-Nut). Environ. Health Perspect. 2017, 125, 409-415. [CrossRef] [PubMed]

11. Offermans, N.S.; Vermeulen, R.; Burdorf, A.; Goldbohm, R.A.; Keszei, A.P.; Peters, S.; Kauppinen, T.; Kromhout, H.; Van Den Brandt, P.A. Occupational asbestos exposure and risk of esophageal, gastric and colorectal cancer in the prospective Netherlands Cohort Study. Int. J. Cancer 2014, 135, 1970-1977. [CrossRef]

12. Gamble, J. Risk of gastrointestinal cancers from inhalation and ingestion of asbestos. Regul. Toxicol. Pharmacol. 2008, 52, S124-S153. [CrossRef] [PubMed]

13. Pass, H.I.; Vogelzang, N.J.; Carbone, M. Malignant mesothelioma. In Advances in Pathogenesis, Diagnosis, and Translational Therapies; Springer Science+Business Media, Inc.: New York, NY, USA, 2005.

14. Anttila, S.; Boffetta, P. Occupational Cancers, 2nd ed.; Springer Nature: Cham, Switzerland, 2020.

15. Serio, G.; Vimercati, L.; Pennella, A.; Gentile, M.; Cavone, D.; Buonadonna, A.L.; Scattone, A.; Fortarezza, F.; De Palma, A.; Marzullo, A. Genomic changes of chromosomes 8p23.1 and 1q21: Novel mutations in malignant mesothelioma. Lung Cancer 2018, 126, 106-111. [CrossRef] [PubMed]

16. Pezzuto, F.; Serio, G.; Fortarezza, F.; Scattone, A.; Caporusso, C.; Punzi, A.; Cavone, D.; Pennella, A.; Marzullo, A.; Vimercati, L. Prognostic Value of Ki67 Percentage, WT-1 Expression and p16/CDKN2A Deletion in Diffuse Malignant Peritoneal Mesothelioma: A Single-Centre Cohort Study. Diagnostics 2020, 10, 386. [CrossRef] [PubMed]

17. Pezzuto, F.; Vimercati, L.; Fortarezza, F.; Marzullo, A.; Pennella, A.; Cavone, D.; Punzi, A.; Caporusso, C.; D’Amati, A.; Lettini, T.; et al. Evaluation of prognostic histological parameters proposed for pleural mesothelioma in diffuse malignant peritoneal mesothelioma. A short report. Diagn. Pathol. 2021, 16, 1-7. [CrossRef]

18. Carbone, M.; Harbour, J.W.; Brugarolas, J.; Bononi, A.; Pagano, I.; Dey, A.; Krausz, T.; Pass, H.; Yang, H.; Gaudino, G. Biological Mechanisms and Clinical Significance of BAP1 Mutations in Human Cancer. Cancer Discov. 2020, 10, 1103-1120. [CrossRef]

19. WHO. Digestive System Tumours. In WHO Classification of Tumours, 5th ed.; WHO: Lyon, France, 2020.

20. Van Zandwijk, N.; Reid, G.; Frank, A.L. Asbestos-related cancers: The 'Hidden Killer' remains a global threat. Expert Rev. Anticancer Ther. 2020, 20, 271-278. [CrossRef]

21. Wolff, H.; Vehmas, T.; Oksa, P.; Rantanen, J.; Vainio, H. Asbestos, asbestosis, and cancer, the Helsinki criteria for diagnosis and attribution 2014: Recommendations. Scand. J. Work Environ. Health 2015, 41, 5-15. [CrossRef]

22. Vainio, H.; Oksa, P.; Tuomi, T.; Vehmas, T.; Wolff, H. Aggiornamento dei Criteri di Helsinki 2014: L'amianto continua a essere una sfida per la prevenzione e l'attribuzione delle patologie. Epidemiol. Prev. 2016, 40, 15-19. [CrossRef]

23. Masse, R.; Sebastien, P.; Monchaux, G.; Bignon, J. Experimental demonstration of the penetration of asbestos fibres into the gastrointestinal tract. IARC Sci. Publ. 1980, 30, 321-328.

24. Selikoff, I.J.; Churg, J.; Hammond, E.C. Asbestos Exposure and Neoplasia. JAMA 1964, 188, 22-26. [CrossRef]

25. Sébastien, P.; Masse, R.; Bignon, J. Recovery of ingested asbestos fibers from the gastrointestinal lymph in rats. Environ. Res. 1980, 22, 201-216. [CrossRef] 
26. Auerbach, O.; Conston, A.S.; Garfinkel, L.; Parks, V.R.; Kaslow, H.D.; Hammond, E.C. Presence of Asbestos Bodies in Organs Other than the Lung. Chest 1980, 77, 133-137. [CrossRef]

27. Huang, Q.; Lan, Y.-J. Colorectal cancer and asbestos exposure-an overview. Ind. Health 2020, 58, 200-211. [CrossRef]

28. Wang, X.; Yano, E.; Lin, S.; Yu, I.T.S.; Lan, Y.; Tse, L.A.; Qiu, H.; Christiani, D.C. Cancer Mortality in Chinese Chrysotile Asbestos Miners: Exposure-Response Relationships. PLoS ONE 2013, 8, e71899. [CrossRef]

29. Clin, B.; Thaon, I.; Boulanger, M.; Brochard, P.; Chamming'S, S.; Gislard, A.; Lacourt, A.; Luc, A.; Ogier, G.; Paris, C.; et al. Cancer of the esophagus and asbestos exposure. Am. J. Ind. Med. 2017, 60, 968-975. [CrossRef]

30. Kjærheim, K.; Ulvestad, B.; Martinsen, J.I.; Andersen, A.; Kjaerheim, K. Cancer of the gastrointestinal tract and exposure to asbestos in drinking water among lighthouse keepers (Norway). Cancer Causes Control 2005, 16, 593-598. [CrossRef]

31. Garcia, J.M.; Rodriguez, R.; Dominguez, G.; Silva, J.M.; Provencio, M.; Colmenarejo, A.; Millan, I.; Muñoz, C.; Salas, C.; Coca, S.; et al. Prognostic significance of the allelic loss of the BRCA1 gene in colorectal cancer. Gut 2003, 52, 1756-1763. [CrossRef]

32. Grabsch, H.; Dattani, M.; Barker, L.; Maughan, N.; Maude, K.; Hansen, O.; Gabbert, H.E.; Quirke, P.; Mueller, W. Expression of DNA Double-Strand Break Repair Proteins ATM and BRCA1 Predicts Survival in Colorectal Cancer. Clin. Cancer Res. 2006, 12, 1494-1500. [CrossRef]

33. Baumann, F.; Flores, E.; Napolitano, A.; Kanodia, S.; Taioli, E.; Pass, H.; Yang, H.; Carbone, M. Mesothelioma patients with germline BAP1 mutations have 7-fold improved long-term survival. Carcinogenesis 2015, 36, 76-81. [CrossRef]

34. Tang, J.; Xi, S.; Wang, G.; Wang, B.; Yan, S.; Wu, Y.; Sang, Y.; Wu, W.; Zhang, R.; Kang, T. Prognostic significance of BRCA1associated protein 1 in colorectal cancer. Med. Oncol. 2013, 30, 541. [CrossRef]

35. Pezzuto, F.; Lunardi, F.; Vedovelli, L.; Fortarezza, F.; Urso, L.; Grosso, F.; Ceresoli, G.L.; Kern, I.; Vlacic, G.; Faccioli, E.; et al. P14/ARF-Positive Malignant Pleural Mesothelioma: A Phenotype With Distinct Immune Microenvironment. Front. Oncol. 2021, 11, 653497. [CrossRef] [PubMed]

36. Fortarezza, F.; Pezzuto, F.; Marzullo, A.; Cavone, D.; Romano, D.E.; D'Amati, A.; Serio, G.; Vimercati, L. Molecular Pathways in Peritoneal Mesothelioma: A Minireview of New Insights. Front. Oncol. 2022, 12, 823839. [CrossRef]

37. Berg, M.; Nordgaard, O.; Kørner, H.; Oltedal, S.; Smaaland, R.; Søreide, J.A.; Søreide, K. Molecular Subtypes in Stage II-III Colon Cancer Defined by Genomic Instability: Early Recurrence-Risk Associated with a High Copy-Number Variation and Loss of RUNX3 and CDKN2A. PLoS ONE 2015, 10, e0122391. [CrossRef] [PubMed]

38. Offin, M.; Yang, S.-R.; Egger, J.; Jayakumaran, G.; Spencer, R.S.; Lopardo, J.; Nash, G.M.; Cercek, A.; Travis, W.D.; Kris, M.G.; et al. Molecular Characterization of Peritoneal Mesotheliomas. J. Thorac. Oncol. 2021. [CrossRef] 